\title{
Inhibited drinking and reduced glucoprivic feeding after 2-deoxy-D-glucose in rats adapted to quinine-adulterated water
}

\author{
P. J. WATSON, SHANNON BEATEY, MICHAEL D. BIDERMAN, and MARTHA L. PIERCE \\ University of Tennessee at Chattanooga, Chattanooga, Tennessee
}

\begin{abstract}
Glucoprivic responsivity after administration of $500 \mathrm{mg} / \mathrm{kg}$ of 2-deoxy-D-glucose (2DG) was evaluated in seven rats adapted to a $0.1 \%$ (w/v) quinine-adulterated water supply. Quinine subjects failed to display a significant drug-induced increase in eating, and 2DG actively inhibited their drinking behavior. Significant but reduced glucoprivic responsivity was observed in a larger sample of quinine-adapted animals treated with 250,500 , and $750 \mathrm{mg} / \mathrm{kg}$ of $2 \mathrm{DG}$; and the drug once again inhibited quinine fluid intake. These data further suggest the importance of considering hydrational factors in analyzing 2DG effects, although other variables, including palatability-related processes and a quinine $\times 2$ DG interaction effect, also appear to be implicated.
\end{abstract}

Recent studies have focused on the ability of thirsty animals to respond to glucoprivic challenges. In addition to clarifying the factors that influence food intake during glucoprivation, these studies are of additional interest because some brain lesions that disturb glucoprivic feeding also produce deficits in drinking behavior (e.g., Epstein, 1971). Neurologically intact subjects normally eat less when in a state of water deprivation (Bolles, 1961), and both insulin and 2-deoxy-D-glucose (2DG) are sufficient triggers of thirst and drinking behavior (Booth \& Pitt, 1968; Welle, Thompson, Campbell, \& Lilavivathana, 1980). These observations suggest that brain-damage effects might reflect, at least in part, a generalized inhibition of feeding by a lesion-induced hydrational deficit instead of a disruption of primary neural glucoprivic controls.

Hypodipsia alone does not disrupt eating evoked by either 2DG (Watson, Biderman, \& Warfield, 1981) or insulin (Watson, Biderman, Pierce, Beatey, Wagner, \& Stahl, 1984). When several days of experience with quinine-adulterated water are used to produce hypodipsia plus an apparent body-water deficit, subjects are less able to eat following 2DG (Watson \& Biderman, 1982). Data suggest that a parallel effect does not follow insulin injections (Watson et al., 1984). The general purpose of the present study was to respond to these contrasting 2DG and insulin effects by reexamining 2DG responsivity in animals with reduced ability to ingest water.

\section{EXPERIMENT 1}

In this experiment, the eating by rats that were well

Conduct of this project was made possible in part by funds obtained from the University of Chattanooga Foundation. Shannon Beatey is now in the psychobiology graduate program of the University of Georgia. Reprint requests should be addressed to P. J. Watson, Department of Psychology, University of Tennessee, Chattanooga, TN 37403. adapted to quinine-adulterated water was monitored following 2DG treatment. Not all investigators have observed thirst-produced deficits in 2DG responsivity (Kanerek, Salomon, \& Khadivi, 1981), and the reliability of the effect was therefore of some concern. In addition, some of the previously reported thirst effects (Watson \& Biderman, 1982) were observed during the severe dehydration and near adipsia that occur during the early stages of access to quinine-adulterated fluid. Of interest was the possibility that rats with subtler, long-term alterations in drinking behavior might experience difficulties in responding to 2DG. Rats with lateral hypothalamic lesions are initially adipsic but do eventually recover limited water-ingestion capacities (Epstein, 1971). However, the 2DG deficit persists (Wayner, Cott, Millner, \& Tartaglione, 1971). Subjects adapted to quinine-adulterated water show altered drinking patterns similar to those of some brain-lesioned animals (Nicolaidis \& Rowland, 1975); if these quinine-adapted subjects were similarly inhibited in their response to 2DG, then a contribution of water-intake abnormalities to the observed lesion effects would be further implicated, although certainly not proven.

\section{Method}

Subjects. Adult male Long-Evans hooded rats served as subjects. Each of the 30 animals was experimentally naive and was selected from the departmental colony. Initial weights ranged from 413 to $580 \mathrm{~g}$, with an average of $520 \mathrm{~g}$.

Procedure. The subjects were individually housed in $7 \times 7 \times 9.5$ in. stainless steel cages. Room temperature was maintained at $72^{\circ} \mathrm{F}$, and lighting was turned on at $0800 \mathrm{~h}$ and turned off at $2000 \mathrm{~h}$. All experimental procedures began at approximately $1300 \mathrm{~h}$.

Assignment to the quinine $(\mathrm{N}=20)$ and the control $(\mathrm{N}=10)$ groups $\propto c$ curred in a quasirandom order that ensured essentially equal starting weights. Animals in the quinine group were given a $0.1 \%(w / v)$ solution of quinine hydrochloride (Sigma Co.) instead of water. Ad-lib fluid and Purina Lab Chow were made available in the home cages throughout all procedures. Quinine-group bodyweights were monitored closely, and subjects that did not drink enough adulterated solution to stabilize their 
weights within 3 weeks were dropped from the investigation. Adaptation to the quinine solution continued for a total of 1 month before experimental procedures began.

Next, the subjects were given 3 days of experience with the basic experimental procedures. They were removed from their home cages, injected intraperitoneally with physiological saline, and placed in experimental cages immediately below the home cages. The rats remained in these cages for $4 \mathrm{~h}$ and had ad-lib access to food. Adulterated fluid was presented to quinine subjects, while controls continued to receive water.

Formal data collection began on the day after the last of these three familiarization trials. Each rat was injected intraperitoneally with a control volume of physiological saline and placed in the experimental cage. $\mathrm{Pu}$ rina Lab Chow pellets, measured to the nearest $0.1 \mathrm{~g}$, were made available; the uneaten portions were removed at hourly intervals, measured, and replaced with a fresh supply. Food dropped through the cage floors was also collected. Total session fluid consumptions were recorded by weighing bottles to the nearest gram before and after the session. Procedures remained unchanged on the next day, except that both groups received $500-\mathrm{mg} / \mathrm{kg}$ 2DG injections, a dosage previously found to be most effective in evoking food intake in rats with limited water-ingestion capabilities.

\section{Results}

Thirteen of the 20 quinine animals failed to adapt to the adulterated water. Most of these were eliminated within the first 2 weeks after their body weights had been reduced by $35 \%$ or more and after their general behavioral activity suggested that they might die if procedures continued. This loss of subjects was higher than that in previous investigations, but a larger number might have been retained had the animals been allowed to continue until they either drank or died. Three subjects were dropped at random from the control group to produce equal sample sizes, and the data therefore reflected the ingestive behavior of seven animals well adapted to the adulterated fluid and of seven with ad-lib access to water. At the time of final experimental analysis, the quinine group weighed $462 \mathrm{~g}$, on the average, whereas the control mean was $541 \mathrm{~g}$.

Because the time-since-injection and the fluidadulteration variables did not interact, only total session feeding amounts are reported. Controls ate $3.64 \pm 0.45 \mathrm{~g}$ (mean \pm SEM) after physiological saline treatment and $9.64 \pm 0.91 \mathrm{~g}$ after $2 \mathrm{DG}$, whereas quinine animals ate $5.00 \pm 0.49 \mathrm{~g}$ and $6.03 \pm 0.54 \mathrm{~g}$, respectively. Data analysis was accomplished with a $2 \times 2$ ANOVA in which the fluid-adulteration effect served as a between-subjects factor and the drug effect served as a within-subjects factor. The group difference in eating failed to reach conventional levels of significance $[F(1,12)=3.43, p>.05]$, but the drug $[\mathrm{F}(1,12)=29.86, \mathrm{p}<.001]$ and the fluid $X$ drug interaction $[F(1,12)=14.94, p<.01]$ effects were reliable. This interaction effect was most noteworthy and appeared to occur because quinine subjects, unlike controls, were only minimally responsive to $2 \mathrm{DG}$. Formal analysis of this possibility was accomplished with correlated $t$ tests, which revealed a drug enhancement in the control $[\mathrm{t}(6)=5.92, \mathrm{p}<.001]$ but not in the quinine $[\mathrm{t}(6)=1.30, \mathrm{p}>.05]$ group.

A $2 \times 2$ ANOVA was also employed to analyze the fluid-intake data; it revealed significant fluid $[\mathrm{F}(1,12)=$ $38.16, \mathrm{p}<.001]$, drug $[\mathrm{F}(1,12)=366.51, \mathrm{p}<.001]$, and fluid $\times$ drug interaction $[F(1,12)=88.34, p<.001]$ effects. Correlated $t$ tests revealed that the interaction was observed because 2DG elevated control fluid intake [ $\mathrm{t}(6)$ $=7.07, \mathrm{p}<.01: 19.57 \pm 0.60 \mathrm{~g}(2 \mathrm{DG}$ mean \pm SEM $)$ vs. $6.71 \pm 1.83 \mathrm{~g}$ (saline mean \pm SEM)] while inhibiting that of the quinine subjects $[\mathrm{t}(6)=5.62, \mathrm{p}<.01$ : $4.29 \pm 0.57 \mathrm{~g}(2 \mathrm{DG}$ mean $\pm \mathrm{SEM})$ vs. $7.14 \pm 0.46 \mathrm{~g}$ (saline mean \pm SEM)].

\section{EXPERIMENT 2}

The possibility that a significant drug effect on food intake might emerge with a larger sample of quinine-adapted animals was examined in Experiment 2; in addition, a wider range of 2DG dosages was explored.

\section{Method}

Subjects. Thirty-eight adult male Long-Evans hooded rats served as subjects. Twenty-four of these were experimentally naive, but 14 others had been used in a previous study (Watson \& Biderman, 1982) that had examined responsivity to insulin during the early stages of experience with quinine-adulterated water. These two groups were run at different times, but their data were combined because their reactions to 2DG were virtually identical. Of the 38 subjects, 22 were in the quinine group and 16 were in the control group. Twenty-five other rats were dropped from the study at various times prior to the injection procedures for failing to adapt to the adulterated fluid. The adaptation rate (22 of 47) therefore was again below $50 \%$ and was roughly comparable to that observed in Experiment 1. Subject weights prior to water adaption averaged $479 \mathrm{~g}$.

Procedure. Housing, adaptation to quinine fluid, and familiarization procedures were generally like those of Experiment 1. The most important procedural alteration involved administration of four injections per subject: saline, 250,500 , and $750 \mathrm{mg} / \mathrm{kg}$ of $2 \mathrm{DG}$. At least 3 days intervened between injections, and the various dosages were presented in a quasirandom order that helped ensure that each injection condition was given as equally as possible on each treatment day. Saline injections were isovolemic with the $500-\mathrm{mg} / \mathrm{kg}$ dosage. One other minor change was made in data-collection procedures in that the subjects were examined in their home cages instead of in cages below. Analysis of food and fluid intakes was accomplished with $2 \times 4$ unequal-N ANOVAs. The two fluid conditions (quinine vs. control) served as a between-subjects variable, and the drug injections operated as a withinsubjects variable.

\section{Results}

At the time of the final experimental session, the rats in the quinine group weighed $461 \mathrm{~g}$, on the average, and those in the control group weighed $504 \mathrm{~g}$. Measures of ingestive behavior for both groups are reviewed in Table 1 . Analysis of the food-intake data indicated that quinine subjects ate less $[\mathrm{F}(1,36)=16.80, \mathrm{p}<.001]$, that $2 \mathrm{DG}$ increased food consumption $[\mathrm{F}(3,108)=16.64$, $p<.001]$, and that the group and drug effects interacted $[F(3,108)=5.03, p<.01]$. The Newman-Keuls test with $p<.05$ was employed to clarify the significant interaction; and within each group, all three drug injections increased food intake over that of the saline treatment. No other within-group differences were significant. Independent $t$ tests comparing the two groups at each injection condition indicated similar reactions to saline $[(t)(36=$ $-.024, \mathrm{p}>.05]$, but significantly higher control intake measures for each 2 DG dosage [all ts $(36) \geq 3.41$, p < $.01]$.

Fluid intake was significantly lower in the quinine 
Table 1

Food and Fluid Intakes of Quinine and Control Groups After 2DG and Saline Injections

\begin{tabular}{llllll}
\hline \multirow{2}{*}{$\begin{array}{l}\text { Dependent } \\
\text { Variable }\end{array}$} & Group & Saline & $250 \mathrm{mg} / \mathrm{kg}$ & $500 \mathrm{mg} / \mathrm{kg}$ & $750 \mathrm{mg} / \mathrm{kg}$ \\
\hline \multirow{2}{*}{ Food Intake } & $\mathrm{C}$ & $2.54 \pm 0.35$ & $4.86 \pm 0.31$ & $5.59 \pm 0.55$ & $5.66 \pm 0.69$ \\
& $\mathrm{Q}$ & $2.67 \pm 0.35$ & $3.30 \pm 0.20$ & $3.66 \pm 0.25$ & $3.48 \pm 0.22$ \\
Fluid Intake & $\mathrm{C}$ & $7.25 \pm 1.49$ & $9.23 \pm 0.96$ & $13.31 \pm 1.51$ & $15.56 \pm 1.95$ \\
& $\mathrm{Q}$ & $5.14 \pm 0.64$ & $3.91 \pm 0.46$ & $3.91 \pm 0.36$ & $3.95 \pm 0.42$ \\
\hline
\end{tabular}

Note $-C=$ control. $Q=$ quinine. Dependent variables are expressed as mean number of grams $\pm S E M$.

animals $[\mathrm{F}(1,36)=71.23, \mathrm{p}<.001]$ and was influenced by the $2 \mathrm{DG}$ injections $[\mathrm{F}(3,108)=7.28, \mathrm{p}<.001]$. However, the drug had different effects in the two groups [group $X$ drug: $F(3,108)=10.88, p<.001$ ], with post hoc analyses revealing an increase for controls at the $500-$ and $750-\mathrm{mg} / \mathrm{kg}$ dosages, but a reduction for the quinine subjects at all three dosages.

\section{GENERAL DISCUSSION}

Rats adapted to quinine-adulterated water evidenced reduced ability to eat after 2DG administration, and these data therefore supplement those presented previously in suggesting that hydrational factors may exert an important influence on 2DG responsivity. Although suggestive, these results nevertheless cannot serve as definitive evidence of an effect dependent solely upon water-intake variables, since the quinine and control groups differed in terms of a number of additional variables. Most obviously, experimentals had access to quinine, whereas controls did not; and quinine adulteration of ingestibles may produce some as yet unspecified malaise effect (see, e.g., Aravich \& Sclafani, 1980 ) that could interfere with glucoprivic feeding. A problem with this suggestion, however, is that quinine adulteration of water fails to disturb insulin-induced food intake (Watson \& Biderman, 1982); use of this adulterant, therefore, is not a sufficient condition for the disruption of feeding triggered by reduced cellular glucose utilization. The interaction between quinine and 2DG could of course be different from that between quinine and insulin, and such a possibility certainly deserves additional attention.

A second contrast between the experimental and control groups was their body weights, with quinine subjects, values averaging $85 \%$ to $91 \%$ of the control subjects' values; other research suggests that this difference could serve as a confound (Sawchenko, Gold, \& Bisson, 1980). At least two arguments can be made against the sufficiency of this variable for disrupting glucoprivic feeding. First, insulin-induced feeding is not blocked by the $10 \%$-body-weight and $25 \%$-food-intake reductions observed during short-term experience with quinine-adulterated water; and second, the brain-lesion literature reveals no necessary covariation between food-intake and body-weight changes, on the one hand, and glucoprivic responsivity, on the other (Dalton, Carpenter, \& Grossman, 1981; Kanarek et al., 1981).

The 2DG-induced inhibition of quinine fluid intake was not predicted and is noteworthy for a number of reasons. First, such an effect could only exacerbate any possible contribution of a hydrational deficit to 2DG hyporesponsivity. Second, reduced drinking is not a sufficient condition for disrupting 2DG glucoprivic feeding because animals given only quinine-adulterated water during testing sessions tend to drink less after 2DG while increasing their food intake in a normal manner (Watson et al., 1981). Limited drinking plus an apparent body-water deficit may be required for the feeding-disruption effect to occur. Third, the inhibited drinking of adulterated water is paralleled by an inhibited eating of adulterated food (Kanarek \& Mayer, 1978); in addition, insulin can enhance, whereas 2DG can retard, consumption of a saccharin solution (Kutscher, Yamamoto, \& Hamburger, 1979). Although palatability fac- tors apparently are also important with insulin (e.g., Vasselli \& Sclafani, 1979), they nevertheless may be more critical with 2DG, at least when quinine and saccharin are the adulterants. Therefore, the possibility exists that palatability variables, instead of or in addition to hydrational factors, were important in this investigation. This possibility is particularly interesting in light of recent demonstrations that manipulation of food palatability is useful in alleviating glucoprivic deficits in brainlesioned animals (Kanarek, et al.; Tepper \& Kanarek, 1984). The results of this investigation therefore also strengthen the need to clarify 2DG influences on palatability-related processes, and efforts in that direction should continue.

\section{REFERENCES}

Aravich, P. F., \& Sclafani, A. (1980). Dietary preference in rats fed bitter tasting quinine and sucrose octaacetate adulterated diets. Physiology \& Behavior, 25, 157-160.

Bolles, R. C. (1961). The interaction of hunger and thirst in the rat. Journal of Comparative and Physiological Psychology, 54, 580-584.

Воотн, D. A., \& PitT, M. E. (1968). The role of glucose in insulininduced feeding and drinking. Physiology \& Behavior, 3, 447-453.

Dalton, L. D., Carpenter, R. G., \& Grossman, S. P. (1981). Ingestive behavior in adult rats with dorsomedial hypothalamic lesions. Physiology \& Behavior, 26, 117-123.

Epstein, A. N. (1971). The lateral hypothalamic syndrome: Its implications for the physiological psychology of hunger and thirst. In E. Stellar \& J. M. Sprague (Eds.), Progress in physiological psychology (Vol. 4). New York: Academic Press.

KANAREK, R. B., \& MAYER, J. (1978). 2-deoxy-D-glucose induced feeding: Relation to diet palatability. Pharmacology, Biochemistry, and Behavior, 8, 615-617.

KANAREK, R. B., SALOMON, M., \& KHADIVI, A. (1981). Rats with lateral hypothalamic lesions do eat following acute cellular glucoprivation. American Journal of Physiology, 241, R362-R369.

Kutscher, C. L., Yamamoto, B. K., \& Hamburger, J. N. (1979). Increased and decreased preference for saccharin immediately following injections of various agents. Physiology \& Behavior, 23, 461-464.

NicolaIdis, S., \& RowlaNd, N. (1975). Regulatory drinking in rats with permanent access to a bitter fluid source. Physiology \& Behavior, 14, 819-824.

Sawchenko, P. E., Gold, R. M., \& Bisson, B. (1980). Depriving or pair feeding intact controls induces some persisting regulatory deficits similar to those of the recovered lateral rat. Journal of Comparative and Physiological Psychology, 94, 128-144.

TEPPER, B. J., \& KANAREK, R. B. (1984). 2-DG-induced glucopenia does elicit feeding in rats with lesions of the zona incerta. Physiology \& Behavior, 32, 441-446.

VASSElli, J. R., \& SClafani, A. (1979). Hyperreactivity to aversive diets in rats produced by injections of insulin or tolbutamide, but not by food deprivation. Physiology \& Behavior, 23, 557-567.

Watson, P. J., \& Biderman, M. D. (1982). Failure of rats deprived of water to increase food intake during glucoprivation induced by 2deoxy-d-glucose. Pharmacology, Biochemistry, and Behavior, 17, 955-959.

Watson, P. J., Biderman, M. D., Pierce, M. L., Beatey, S., WAGNER, F., \& STAHL, T. (1984). Glucoprivic responsivity after insulin in hypodipsic and in water deficit rats. Life Sciences, 34, 625-630.

Watson, P. J., Biderman, M. D., \& Warfield, D. R. (1981). Eating induced by injections of 2-deoxy-d-glucose in neurologically intact hypodipsic rats. International Journal of Neuroscience, 15, 95-98.

Wayner, J. J., Cott, A., Millner, J., \& Tartaglione, R. (1971). Loss of 2-deoxy-d-glucose induced eating in recovered lateral rats. Physiology \& Behavior, 7, 881-884.

Welle, S. L., Thompson, D. A., Campbell, R. G., \& Lilavivathana, U. (1980). Increased hunger and thirst during glucoprivation in humans. Physiology \& Behavior, 25, 397-403.

(Manuscript received for publication October 8, 1984). 